\title{
Studies of Nerve-Muscle Interactions in Xenopus Cell Culture: Fine Structure of Early Functional Contacts
}

\author{
JoAnn Buchanan, Yi-an Sun, ${ }^{a}$ and Mu-ming Poon \\ Section of Molecular Neurobiology and Howard Hughes Medical Institute, Yale University School of Medicine, New \\ Haven, Connecticut 06510
}

\begin{abstract}
We have studied the fine structure of nerve-muscle contacts during the first few hours of synaptogenesis in embryonic Xenopus cell cultures. The precise timing of contact was achieved by manipulating isolated spherical myocytes (myoballs) into contact with growth cones or neurites of co-cultured spinal neurons. The contacts were shown to be functional by whole-cell voltage-clamp recording of nerve-evoked synaptic currents in the muscle cell. The ultrastructure of these functional contacts was examined by thin-section electron microscopy. In total, 20 nerve-muscle pairs were studied with contact periods ranging from $20 \mathrm{~min}$ to $12 \mathrm{hr}$, during which time a substantial increase in the amplitude of synaptic currents occurred. The structure of noncontacting cells and of nerve-muscle contacts formed between the cells by natural encounters in 1-d-old cultures were also examined in order to identify the features and the time course of morphological differentiation of early functional contacts. Prominent features of the contact area during the first few hours included: close apposition of the nerve and muscle membranes, greater frequency of coated pits and vesicles, and thickening of postsynaptic muscle membrane. Occasionally, clusters of clear vesicles occurred near presynaptic membrane, but no further sign of active zone differentiation was observed. In comparison, definitive active zone structure, well-formed extracellular basal lamina, and widened cleft were seen in natural contacts less than $24 \mathrm{hr}$ old. This study of the identified functional contacts may help us to understand the structural basis for early nerve-muscle interaction and the functional significance of various synaptic specializations.
\end{abstract}

The mature neuromuscular synapse is characterized by many cellular specializations. In the nerve terminal, synaptic vesicles are clustered near the electron-dense presynaptic membrane called the active zone. Postsynaptically, there is formation of junctional folds directly opposite the active zones. Specific molecules are localized in the cytoplasm and the plasmalemma of

\footnotetext{
Received Apr. 14, 1988; revised July 25, 1988; accepted Sept. 25, 1988.

We thank Prem Thomas for photographic assistance and June Forella for help with culture preparations, and Dr. Ann Cornell-Bell for helpful discussion. This work was supported by the Howard Hughes Medical Institute, National Institutes of Health (NS 22764), and National Science Foundation (BNS 8509336).

Correspondence should be addressed to JoAnn Buchanan at the above address.

a Present address: Department of Biology, Yale University, New Haven, CT 06520.

Present address: Department of Biological Sciences, Fairchild Center, Columbia University, New York, NY 10027.

Copyright (C) 1989 Society for Neuroscience $0270-6474 / 89 / 051540-15 \$ 02.00 / 0$
}

the junctional region as well as in the extracellular matrix (Dennis, 1981; Sanes, 1983). Previous studies of the morphology of developing synapses in vivo (Teräväinen, 1968; Kelly and Zacks, 1969; Kullberg et al., 1977) and in vitro (Nakajima et al., 1980) have suggested that early synaptic contacts show little evidence of specialization, with various synaptic structures appearing days or even weeks after innervation. Studies using Xenopus cultures, where the timing of nerve-muscle contact is better defined, have shown the appearance of morphological specializations during the first day of culture (Weldon and Cohen, 1979; Takahashi et al., 1987). In contrast, functional synaptic transmission appears soon after nerve-muscle contact. In Xenopus embryos, spontaneous miniature endplate potentials and nerve-evoked endplate potentials were observed within a few hours after the innervation of the myotomal muscle (Blackshaw and Warner, 1976; Kullberg et al., 1977). In Xenopus cultures, these synaptic potentials were observed at the muscle cell within a few minutes or even a few seconds after the neurite-muscle contact (Kidokoro and Yeh, 1982; Chow and Poo, 1985; Xie and Poo, 1986; Sun and Poo, 1987). Moreover, a recent study of the early synapse (Evers et al., 1989, accompanying paper) showed that a significant increase in the efficacy of synaptic transmission occurred during the first $20 \mathrm{~min}$ of nerve-muscle contact. Over a similar period, there was also a marked increase in nerve-muscle adhesion. It was of interest to know whether there was any morphological basis responsible for these synaptic changes, even though the mature synaptic specializations have not appeared at this early time.

This study of early events required precise timing of nervemuscle contact, which was achieved by manipulating muscle cells into contact with growing neurites. Physiological recording of nerve-evoked synaptic currents ensured that the contact identified for ultrastructural study was functional. This approach has allowed us to identify several early morphological features that could provide the structural basis for early nerve-muscle interactions and for the changes in synaptic efficacy. In addition, comparison between the natural and manipulated contacts revealed a temporal sequence of the emergence of these specializations. Some of the results have been reported previously in a brief form (Buchanan et al., 1987).

\section{Materials and Methods}

Cell culture and manipulation. The method of preparing dissociated spinal neurons and myotomal muscle cells from 1-d-old Xenopus embryos (stage 22-24, Nieuwkoop and Faber, 1967) was similar to those previously described (Spitzer and Lamborghini, 1976; Anderson and Cohen, 1977). Cells were plated on clean, uncoated glass coverslips and cultured at room temperature $\left(22^{\circ} \mathrm{C}\right)$ for $18-24 \mathrm{hr}$ before use. The culture medium consists of 50\% (vol/vol) Leibovitz L-15 medium (GIBCO), 

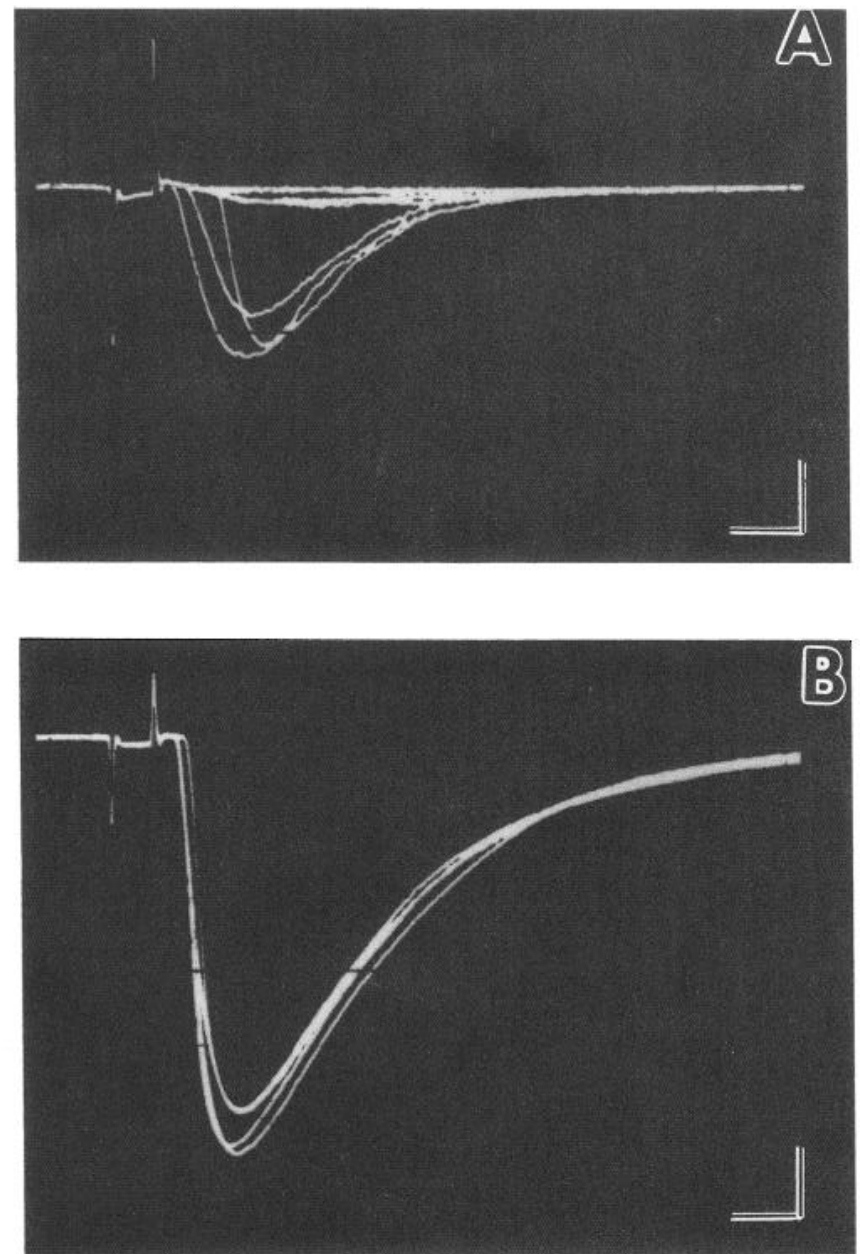

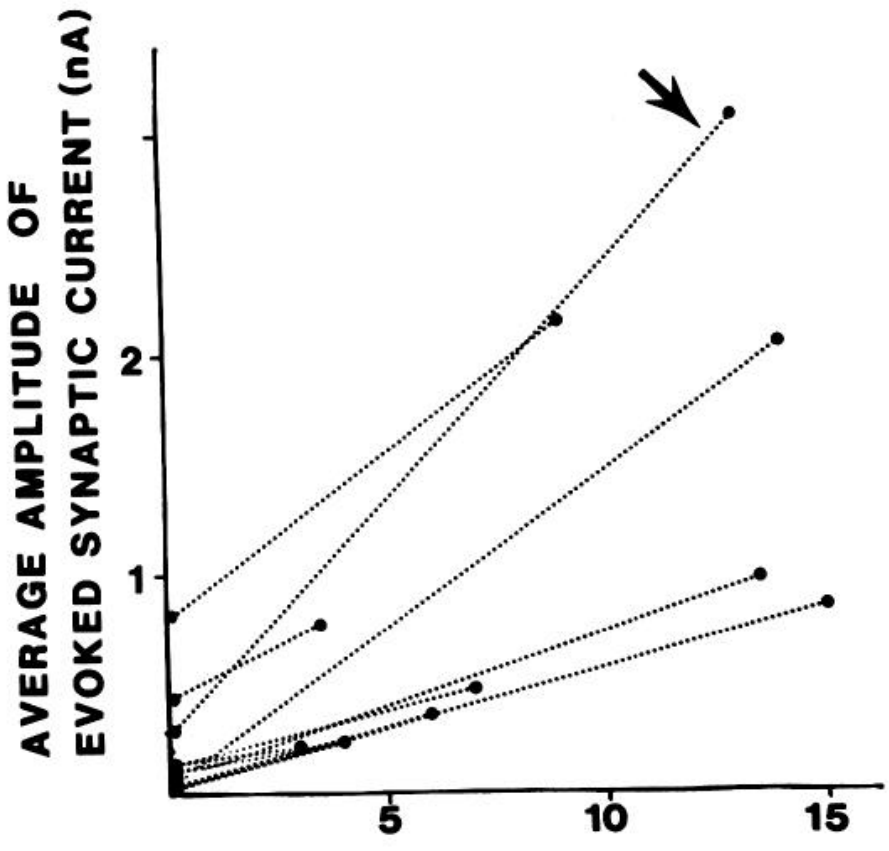

TIME OF CONTACT (HR)

Figure 1. Postcontact changes in the evoked synaptic response. $A$ and $B$, Samples of evoked synaptic currents at the beginning $(A)$ and the end $(B)$ of a $13 \mathrm{hr}$ contact. Data corresponding to the line marked with arrow in $C$. Scales: $2 \mathrm{msec}, 250 \mathrm{pA}$ in $A$ and $2 \mathrm{msec}, 500 \mathrm{pA}$ in $B$. $C$, Wholecell voltage-clamp recordings of synaptic currents at the beginning and the end of contact periods. Data from 10 nerve-muscle contacts were plotted. Each point represents the average amplitude calculated from at least 10 measurements of synaptic currents.

$2 \%$ (vol/vol) fetal calf serum (GIBCO), and 48\% (vol/vol) of Ringer's solution (115 mM NaCl, $2 \mathrm{~mm} \mathrm{CaCl}, 2.5 \mathrm{~mm} \mathrm{KCl}, 10 \mathrm{~mm}$ Hepes, pH 7.3). The cell manipulation procedure was similar to that described by Chow and Poo (1985). For our experiments, the myoball was placed directly on top of the growth cone, with the center of the myoball contacting the interface of the central and peripheral cytoplasmic domains (as defined by Forscher et al., 1987) of the growth cone.

Electrophysiology. Establishment of functional synaptic transmission was monitored by recording evoked synaptic currents in the neuritecontacted muscle cells. The neuron was stimulated electrically at the soma by a heat-polished extracellular glass microelectrode with brief suprathreshold stimuli at a frequency of about $0.2 \mathrm{~Hz}$. Evoked synaptic currents were recorded in the muscle cell by using gigaohm-seal, wholecell voltage-clamp method (Hamill et al., 1981), similar to that described in the previous report (Xie and Poo, 1986). For most of the manipulated neurite-myoball contacts that had been examined by electron microscopy, 2 separate recordings were made: one during the first $15 \mathrm{~min}$ of contact and the other near the end of the contact period (prior to fixation). The first recording ensured that initial functional contact was made, and the second recording examined the changes in the synaptic function during the contact period. The recording patch electrode was removed from the cell after the first recording to avoid electrode-induced intracellular changes. For natural neurite-muscle contact, only the latter recording was made. During the experiment, video microscopic images were recorded in order to facilitate later identification of the cells for electron microscopy.

Electron microscopy. The cells were fixed in 2\% glutaraldehyde (EMS, Ft. Washington, PA) in $0.1 \mathrm{M}$ cacodylate buffer at $380 \mathrm{mOsm}$ and $\mathrm{pH}$
7.4 for $20 \mathrm{~min}$ at room temperature. The fixative was gradually added to the culture dish before the recording electrode was removed from the muscle to avoid possible mechanical perturbation of the contact due to pipet withdrawal. After washing in buffer at the same osmolarity, the cultures were further processed according to the method of McDonald (1984). The glass coverslips were embedded in Embed 812 (EMS, Ft. Washington, PA) using the recipe of Coulter (1967). To aid the removal of the glass coverslip with hydrofluoric acid (Moore, 1975), strips of the fluoropolymer Aclar (Allied Chemical) were placed around the edges of the coverslip before embedding in a Chang embedding mold (Polysciences, Ft. Washington, PA). The polymerized Epon wafers were stained with toludine blue and examined with phase-contrast optics. Identified cells with physiological recording were cut out and reattached to blank stubs using Epon. Cells were cut parallel to the coverslip surface in serial fashion and mounted on Formvar-coated slot grids. Usually, only 35-40 silver sections were taken, representing approximately $2.5 \mu \mathrm{m}$ of tissue. This allowed for the whole growth cone, thin neurites, and filopodia to be cut through. The grids were poststained in uranyl acetate and lead citrate and examined at $60 \mathrm{kV}$ in a Jeol $100 \mathrm{CXII}$ electron microscope.

\section{Results}

\section{Physiology of early functional contacts}

Previous studies have shown that when spherical Xenopus muscle cells (myoballs) were manipulated into contact with co-cultured neurons, nerve-evoked synaptic currents were recorded 
within the first few minutes, suggesting rapid development of functional synapses (Sun and Poo, 1987). In the present study, we have examined the changes in the evoked synaptic currents during the first $12 \mathrm{hr}$ after the manipulated contact, the period for which the ultrastructure of nerve-muscle contact was studied. In all, 10 successful repeated recordings on the same cell pairs were made at the beginning and the end of the contact period. Samples of recordings from one cell pair is shown in Figure $1, A, B$. The result, as presented in Figure $1 C$, showed a slow but steady increase in the average amplitude of the synaptic currents. The range of increase varied between $4-$ and 10-fold. The lower average amplitude at the first recording was due, in part, to the higher rate of transmission failure. With increasing contact time, there was a gradual reduction of amplitude fluctuation between successive synaptic currents, suggesting increasing stability of synaptic transmission. Only cell pairs that exhibited functional transmission were used for ultrastructural examination.

\section{Structure of isolated neurons and muscle cells}

We first studied the fine structure of the isolated (noncontacting) neurite-bearing neurons and muscle cells in 1-d-old Xenopus cultures. These results were used later in determining contactinduced morphological changes.

We found that isolated neurites and growth cones in our cultures exhibited many features previously described for other neuronal types (Yamada et al., 1971; Landis, 1983; Tosney and Wessells, 1983) and for Xenopus neurons in vivo as well as in culture (Kullberg et al., 1977; Weldon and Cohen, 1979). These included microtubules, actin filaments, $50-70 \mathrm{~nm}$ clear vesicles and 90-120 nm dense-core vesicles. Figure 2, $A, B$, shows an isolated neurite in 1-d-old Xenopus culture, at different magnifications. In this and other cases, clear vesicles were either dispersed or clustered. They showed no apparent preferential association with the plasma membrane.

Isolated muscle cells were characterized by a uniform surface morphology and varying degrees of myofibrillar organization. The latter was organized into longer segments of sarcomeres in spindle-shaped muscle than in the myoball. With routine uranyl acetate and lead staining, no clear basal lamina was discerned, although random patches of electron-dense material were seen on the cell surface at higher magnification (Fig. 2C).

\section{Structure of the manipulated contacts}

For study of the morphology of early contacts, the myoball was manipulated into contact with the growth cone for 20,40 , or $50 \mathrm{~min}$ before fixation. For each of these cases, one recording of the evoked synaptic currents was made at the end of the contact period to ensure that functional contact had been maintained. Figure $3 A$ shows phase-contrast, light microscopic image of the cells. At the onset of the experiment, the neuron had already contacted a number of muscle cells that were spontaneously contracting as a result of innervation. A myoball was manipulated into contact with the growth cone of the neuron for a period of $20 \mathrm{~min}$ (see asterisk, Fig. $3 A$ ). Figure $3 B$ shows samples of recordings of evoked synaptic currents at the end of $20 \mathrm{~min}$. Examination of the ultrastructure of this particular contact showed that a small area of the muscle was in contact with the neurite, and there was little evidence of membrane specializations (Fig. 3C). The neurite contained clear vesicles near the site of contact, although no preferential accumulation was apparent (Fig. 3D).
Results for a contact of 40 min duration are shown in Figures 4 and 5. The light microscopic image of the cells and samples of evoked synaptic currents recorded prior to fixation is shown in Figure $4 A$ and $4 B$, respectively. All sections were retrieved and examined for this sample. Figure $4 C$ shows, at low magnification, that the neurite had made extensive contact with the myoball. Several sites of close membrane apposition were seen along the length of contact zone. At higher magnification (Fig. $4 D$ ), one of these sites, which resembled a focal contact, was characterized by a narrow intervening space between the contacting membranes, measuring 5-20 nm. Focal contacts and focal adhesion sites (seen in Fig $8 B$ ) are membrane-associated specializations described in locomoting cultured cells at areas of substratum attachment (Abercrombie et al., 1971; Bloch and Geiger, 1980; Woods et al., 1983). The sites are characterized by discrete areas of adherent cell membrane separated from the substratum by a gap of $15 \mathrm{~nm}$ or less, with an association of cytoplasmic filaments, and a higher density of coated pits in the contacting membrane, all of which have been observed in early nerve-muscle contacts.

Figure $5 A$ shows another, larger area of contact, with many coated membrane structures in both the nerve and muscle cell membranes. Higher magnification of the boxed area (Fig. $5 B$ ) shows a protrusion of the neuritic process that appeared to be engulfed by a coated pit on the muscle surface. The neurite contained clear and dense-core vesicles (Fig. 5C, a later serial section than $5 A$ ). In this area of contact, furthest from the growth cone (second asterisk, next to $\mathrm{N}$ in Fig. $4 C$ ), there was an apparent accumulation of vesicles against the presynaptic membrane. Figure $5 D$ shows this region at higher magnification. Similar accumulations were also seen for a 50 min nerve-muscle contact. These accumulations were not associated with increased density of presynaptic membrane; whether their occurrence near the membrane was related to the development of active zones is unknown.

An example of a $3 \mathrm{hr}$ contact is shown in Figure 6. Samples of synaptic currents at the beginning and the end of the $3 \mathrm{hr}$ period and light microscopic images of the cells are shown in Figure $6, A-D$. Figure $6 E$ shows a low-magnification micrograph of the neurite and the myoball contacting one another. Higher magnification of the contact area shows marked thickening of postsynaptic muscle membrane at certain regions (Fig. $6 F$ ). This membrane thickening resembled that associated with acetylcholine receptor (AChRs) clusters observed in other studies (Burrage and Lentz, 1981). We noted that, like the AChRs clusters induced by the neurite contact (Anderson and Cohen, 1977), the muscle membrane thickening extended beyond the edges of nerve-muscle contact (see Fig. $6 F$, arrowheads). Formation of coated pits at the contact site was again a prominent feature. No coated pits were found at noncontacted regions for all the sections examined. Both clear and dense-core vesicles were seen in the presynaptic zone, without noticeable accumulation at the contact zone opposite to the region of muscle membrane thickening. Along the contact region, a narrow and highly uniform gap of about $20 \mathrm{~nm}$ between the membranes was observed (see Fig. $6 G$ ). As compared with the contacts of 20-50 min duration, where membrane appositions with intervening gaps less than $10 \mathrm{~nm}$ were common, the gap at the $3 \mathrm{hr}$ contact was wider. At regions of muscle membrane thickening, flocculant material was visible within the gap (Fig. $6 F$ ), suggesting selective deposition of extracellular material at the contact site.

Contacts between 3 and $12 \mathrm{hr}$ duration showed morphological 

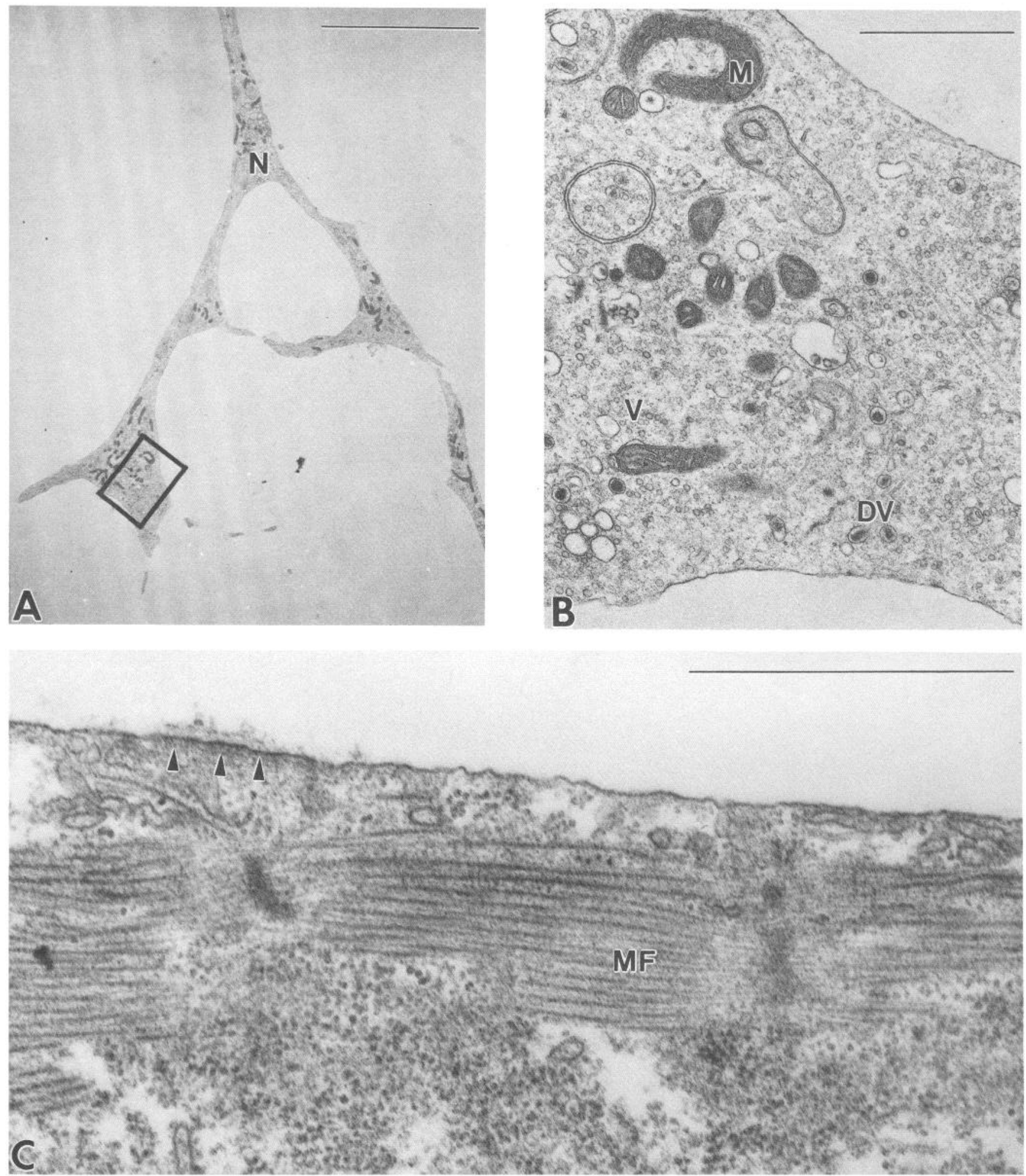

Figure 2. A, Low-magnification micrograph of uncontacted neurite $(N)$ in 1-d-old Xenopus culture. Scale bar, $10 \mu \mathrm{m}$. $B$, Enlargement of the boxed area in the growth cone shown in $A$. Note clusters of $50 \mathrm{~nm}$ clear vesicles $(V)$, mitochondrion $(M)$, and $90 \mathrm{~nm}$ dense-cored vesicles $(D V)$. Scale bar, $1 \mu \mathrm{m}$. $C$, Uncontacted muscle cell showing myofibrils $(M F)$. Note patchy deposition of flocculent material along membrane (arrowheads). Scale bar, $1 \mu \mathrm{m}$.

features similar to, but variable, with respect to those described above for $3 \mathrm{hr}$ contact. In a $12 \mathrm{hr}$ manipulated contact, patches of basal lamina were evident on the muscle surface at the sites of neurite contact (data not shown). For all manipulated contacts examined, the most consistent feature was the frequent occurrence of coated pits and coated vesicles. This was also true for natural neurite-muscle contacts (see following section). In order to quantify this observation, we chose 45 micrographs from 

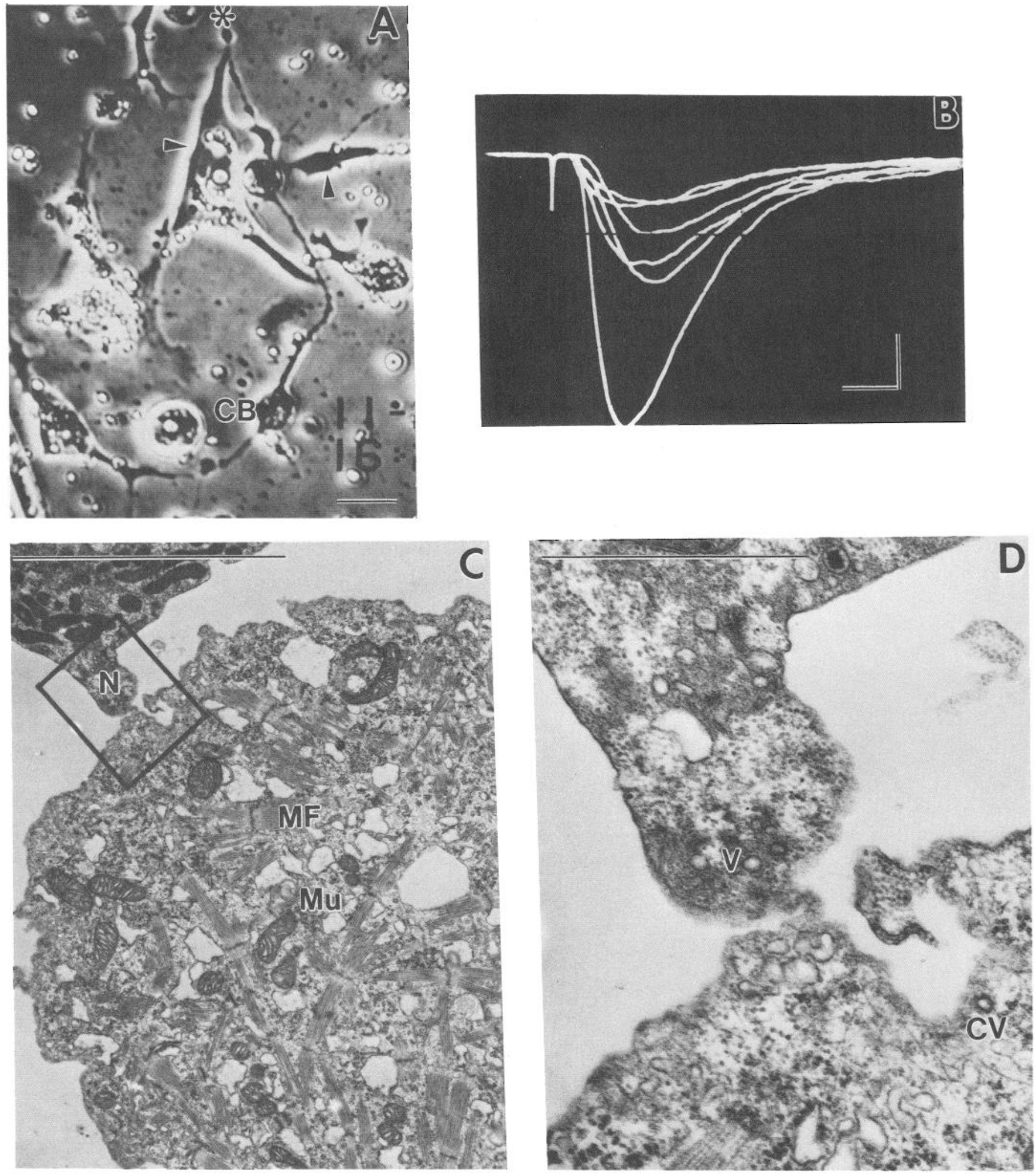

Figure 3. Micrographs of 20 min contact. A, Light-microscopic image of a Xenopus spinal neuron in contact with several co-cultured muscle cells. Asterisk marks the tip of a growth cone where a myoball was placed. Neuron cell body is indicated $(C B)$. Arrowheads indicate positions of other muscle cells innervated by this same neuron. Scale bar, $30 \mu \mathrm{m}$. $B$, Whole-cell voltage-clamp recordings of evoked synaptic currents at the end of 20 min contact. (Synaptic transmission was found immediately upon myoball contact, initial recording not shown.) Scales: 5 msec, 100 pA. $C$, Low-magnification micrograph shows the contact between myoball $(M u)$ and neurite $(N) ; M F$, myofibrils. Scale bar, $5 \mu \mathrm{m}$. $D$, Enlargement of boxed area in $C$ showing clear $50 \mathrm{~nm}$ vesicles $(V)$ in the neurite at site of contact and coated vesicle $(C V)$ in the myoball. Scale bar, $1 \mu \mathrm{m}$. 

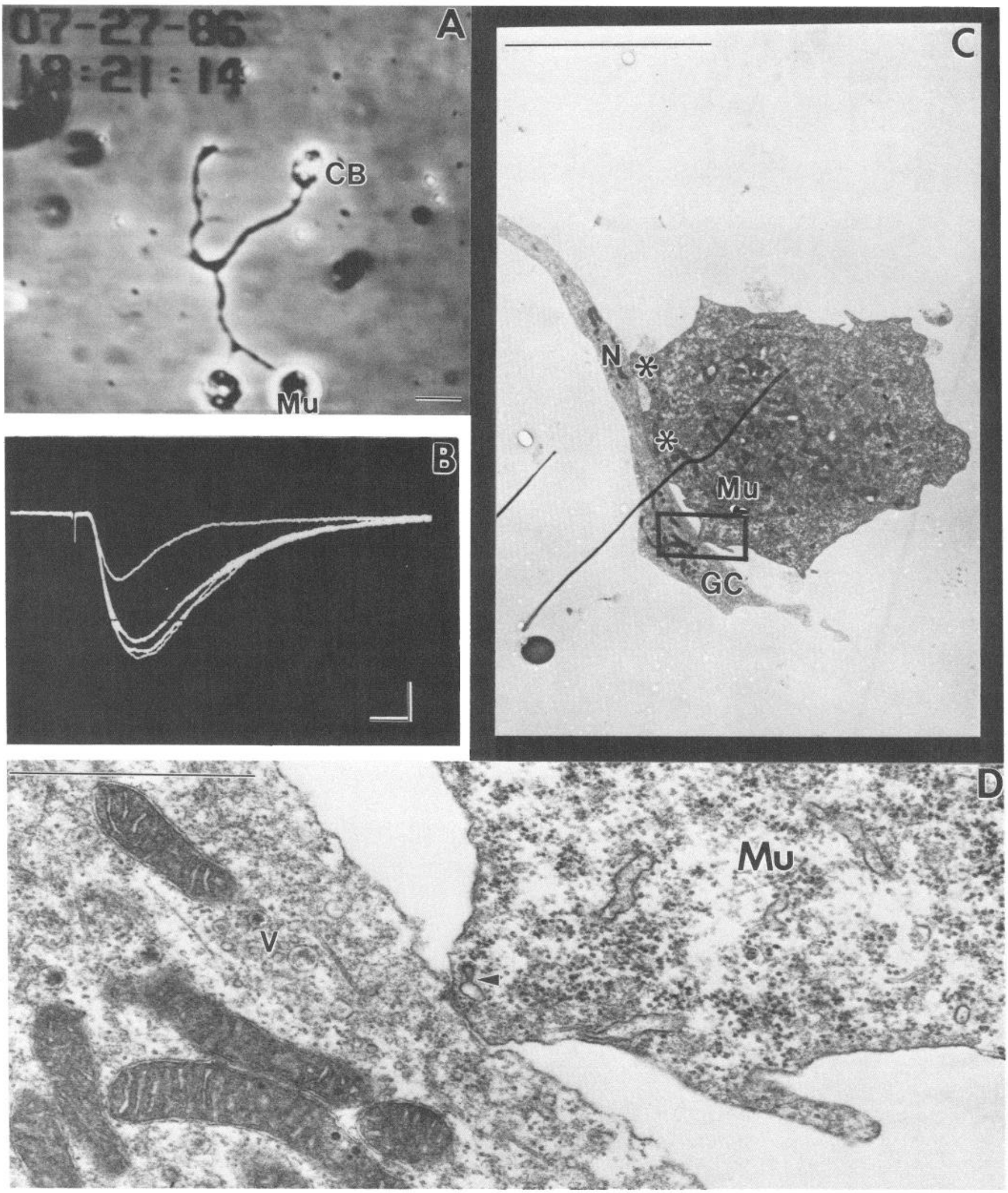

Figure 4. Micrographs of 40 min contact. $A$, Light-microscopic image of a manipulated neurite-muscle pair. Neuron cell body is indicated (CB). Scale bar, $30 \mu \mathrm{m}$. B, Whole-cell voltage-clamp recording of evoked synaptic currents at the end of 40 min contact. Scales: $5 \mathrm{msec}, 100 \mathrm{pA}$. $C$, Lowmagnification micrograph of a neurite $(N)$ and a growth cone $(G C)$ in contact with myoball $(M u)$. Asterisks mark contact areas shown in Figure 5 . Scale bar, $5 \mu \mathrm{m}$. D, Higher magnification of the boxed area in $C$, showing focal contact between neurite and muscle. Note clear $50 \mathrm{~nm}$ vesicles $(V)$ in neurite and coated vesicle joined to a membranous structure in the myoball (arrowhead). Scale bar, $1 \mu \mathrm{m}$. 

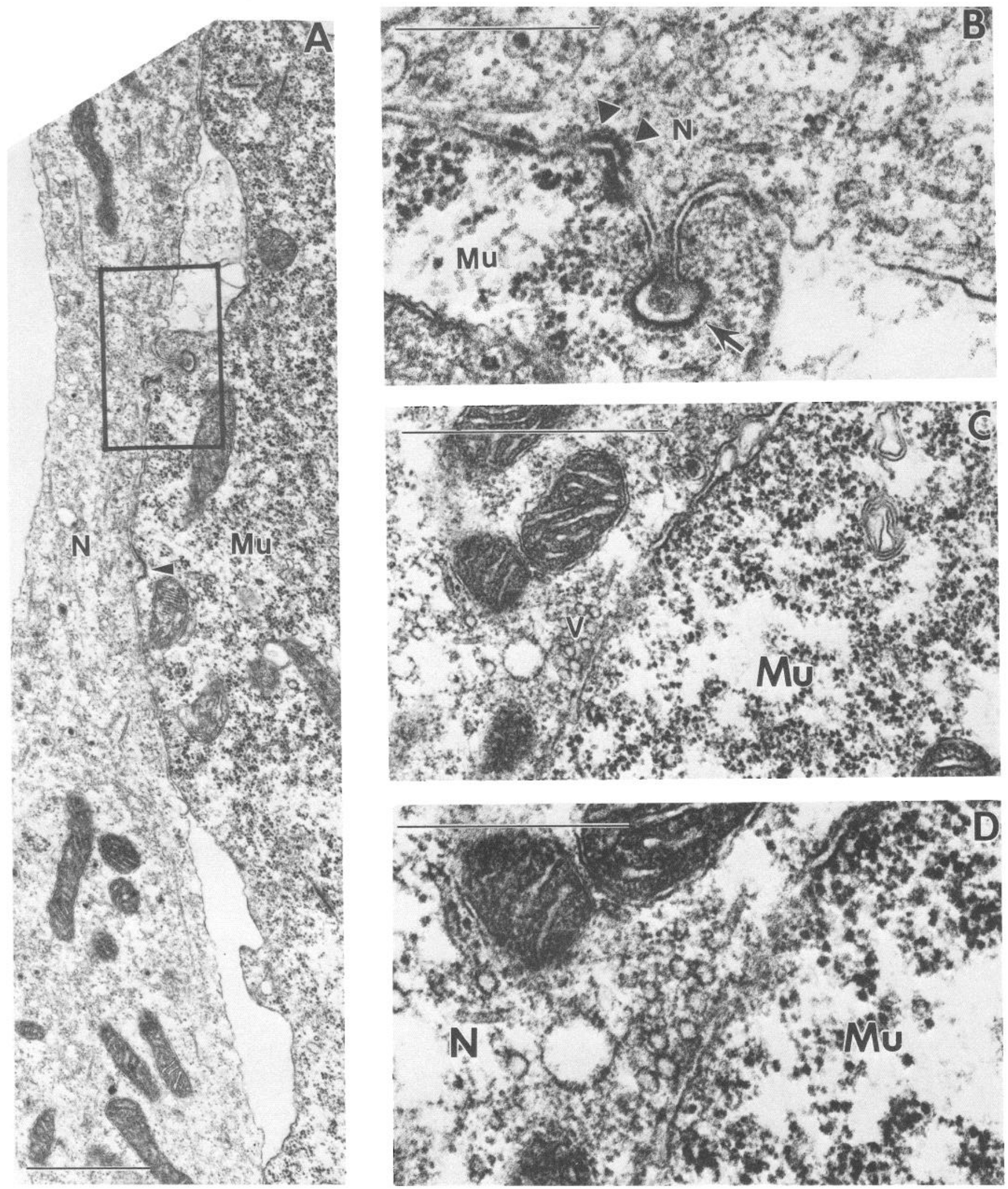

Figure 5. Micrographs of 40 min contact. A, Adjacent section from same sample as that shown in Figure 4 . Note coated pits and vesicles in both nerve $(N)$ and muscle $(M u)$ cells (see boxed area and arrowhead). Scale bar, $1 \mu \mathrm{m}$. B. Higher magnification of boxed area in $A$ reveals portion of the neurite $(N)$ engulfed by long-necked coated pit (arrow) in the myoball $(M u)$. Note coated pits on opposing membranes $(a r r o w h e a d s)$. Scale bar, $500 \mathrm{~nm}$. $C$, Another micrograph for the area marked by the asterisk next to $N$ in Figure $4 C$, showing the presence of $50 \mathrm{~nm}$ clear vesicles ( $V$ ) against presynaptic nerve membrane. Scale bar, $1 \mu \mathrm{m}$. $D$, Higher-magnification micrograph of $C$. Gap at contact site measures about $5 \mathrm{~nm}$. Scale bar, $500 \mathrm{~nm}$. 
data collected for 15 separate contacts and examined the occurrence of coated pits at contacting and noncontacting regions. In 6 out of 45 micrographs, coated pits were found at the contact sites while none were found at noncontacted regions. For the same set of micrographs, we also counted the number of coated vesicles per unit volume in the cytoplasm of the muscle cell within $1 \mu \mathrm{m}$ from the membrane in these regions. The average number of coated vesicles of the muscle cytoplasm in contact regions was $6.2 / \mu \mathrm{m}^{3}$ (range, $0-22.8$ ). For noncontact regions, this number was $1.0 / \mathrm{\mu m}^{3}$ (range, $0-10.8$ ). Although we frequently observed coated vesicles and pits in neurites at contact sites, we were unable to quantify any contact-dependent change. This was because the complex geometry of neuritic processes made it difficult to measure noncontact membrane areas for comparison with contact areas.

\section{Structure of natural contacts}

We have examined the fine structure of natural contacts in 1-d-old Xenopus cultures. These were contacts resulting from random encounters between the growing neurites and the cocultured muscle cells. Some of the morphological features observed at these natural contacts were similar to those described above for manipulated contacts. Because of the haphazard nature of nerve-muscle encounter, the precise age of natural contacts was not known. In 18-24 hr cultures used in this study, the contacts wcrc probably less than $18 \mathrm{hr}$ old, since there was usually a 4-6 hr lag time between cell plating and the onset of neurite outgrowth. During a natural encounter, neurites that had contacted spindle-shaped muscle cells usually continued to grow. Natural contacts made along the muscle surface this way may thus be different in age: Contacts near the growing tip of the neurite were most likely younger than those further away. Therefore, examination of various contact areas along the length of a neurite, which had made extensive contact with a spindleshaped muscle cell, may reveal sequential stages of morphological differentiation of the synapse.

A series of micrographs was obtained from a set of contacts formed between a nerve cell and 5 different muscle cells, including a manipulated myoball. Contact with this myoball was made for $20 \mathrm{~min}$ and has been described earlier (Fig. 3). In the following, we describe 2 of the remaining natural contacts. Figure 7 shows a filopodial contact at high and low magnification. The thin neurite contained $50 \mathrm{~nm}$ clear vesicles. Coated pits were found in the muscle membrane at the contact area. Figure $8 A$ is a low-magnification micrograph of a spindle muscle cell contacted by a neurite. Higher-magnification photographs along the length of the muscle revealed a sequence of distinctly different morphologies. Just behind the growth cone, there was a focal adhesion site between the nerve and muscle cell membranes, with a gap of about $8 \mathrm{~nm}$ (Fig. $8 B$ ). At this focal area, there was an increased electron density of the apposing membranes and an association of microfilament bundles in the muscle cell cytoplasm. Less than $10 \mu \mathrm{m}$ behind the focal adhesion site, there was marked thickening and slight infolding of the muscle membrane (Fig. $8 C$, arrowheads). The gap ranged between 10 and $20 \mathrm{~nm}$. In 2 other regions further away from the growth cone, where a longer contact period between the neurite and the muscle was likely to have occurred, more advanced stages of synaptic specialization were observed. In Figure $9 \mathrm{~A}$ the gap at the contact site measured $10 \mathrm{~nm}$ and contained electron-dense material. The muscle membrane bore ridges which were also electron-dense in appearance. In the cytoplasm of the neurite opposite these ridges, a higher density of clear vesicles was seen near the plasma membrane. Finally, in Figure $9 B$, a clearly specialized active zone type of structure was seen. This included a clustering of clear vesicles against the presynaptic membrane, a $50 \mathrm{~nm}$ gap that contained well-formed hasal lamina, and increased electron density of the postsynaptic membrane.

\section{Discussion}

Sequence of morphological changes at the early contact Combining the results from the manipulated and natural contacts, we have deduced the following sequence of morphological changes during the first day of nerve-muscle contact. In the first tens of minutes, as nerve-muscle adhesion develops, close membrane appositions between the nerve and muscle membranes form, with the extracellular gap measuring less than $10 \mathrm{~nm}$. Such close membrane appositions start at focal points and spread gradually into a larger area as if 2 membranes are "zippered" together. During the same period, coated pits arise in both the nerve and muscle membranes at the region of close apposition, leading to the formation of coated vesicles in the cytoplasm. During the following hours, "thickening" of the postsynaptic membrane occurs, suggesting local accumulation of membraneassociated material, such as acetylcholine receptors (Anderson and Cohen, 1977). Basal lamina-like material starts to be deposited at the contact zone, accompanied by a widening of the gap between the nerve and muscle membranes. During the first $12 \mathrm{hr}$, clear vesicles are distributed throughout the cytoplasm of the neurite. Groups of vesicles occur occasionally near the unspecialized presynaptic membrane of contact regions. Active zone-like structures, including a well-defined basal lamina, and a 50-nm-wide synaptic cleft appear during the second half of the first day. This proposed sequence of events is consistent with various findings on similar developing neuromuscular junctions (Kullberg et al., 1977; Peng et al., 1979, 1980; Nakajima et al., 1980; Anderson et al., 1984; Takahashi et al., 1987). Moreover, our study has provided a detailed description of very early morphological changes occurring within the first few hours of functional contact.

\section{Close membrane appositions}

Close membrane apposition is a common feature of the early nerve-muscle contacts. Such close contact between nerve and muscle cells has been observed at many developing neuromuscular junctions (Kelly and Zacks, 1969; Kullberg et al., 1977; Matthews-Bellinger and Salpeter, 1983). In the present study, we have estimated that, during the first hour of contact, the center-to-center distance between the membranes was usually less than $10 \mathrm{~nm}$. In some cases, no gap can be discerned. Taking the bilayer thickness of $7 \mathrm{~nm}$, the gap between the 2 surfaces was thus less than $3 \mathrm{~nm}$. Such close apposition may allow direct interaction between integral membrane components bound to the opposing membranes. The $\mathrm{ACh}$ receptors in the muscle membrane, for example, protrude substantially into the extracellular space (Rosenbluth, 1974; Rash et al., 1978; Changeux et al., 1984; McCarthy et al., 1986) and are likely to be accessible to binding of molecules on neuronal surfaces. Such interaction could be responsible for the recognition and development of selective adhesion between the nerve and muscle cells.

The identification of focal contacts and focal adhesion sites between the neurites and muscle cells confirms the role of adhesion in the process of synaptogenesis. In fibroblasts, small ad- 

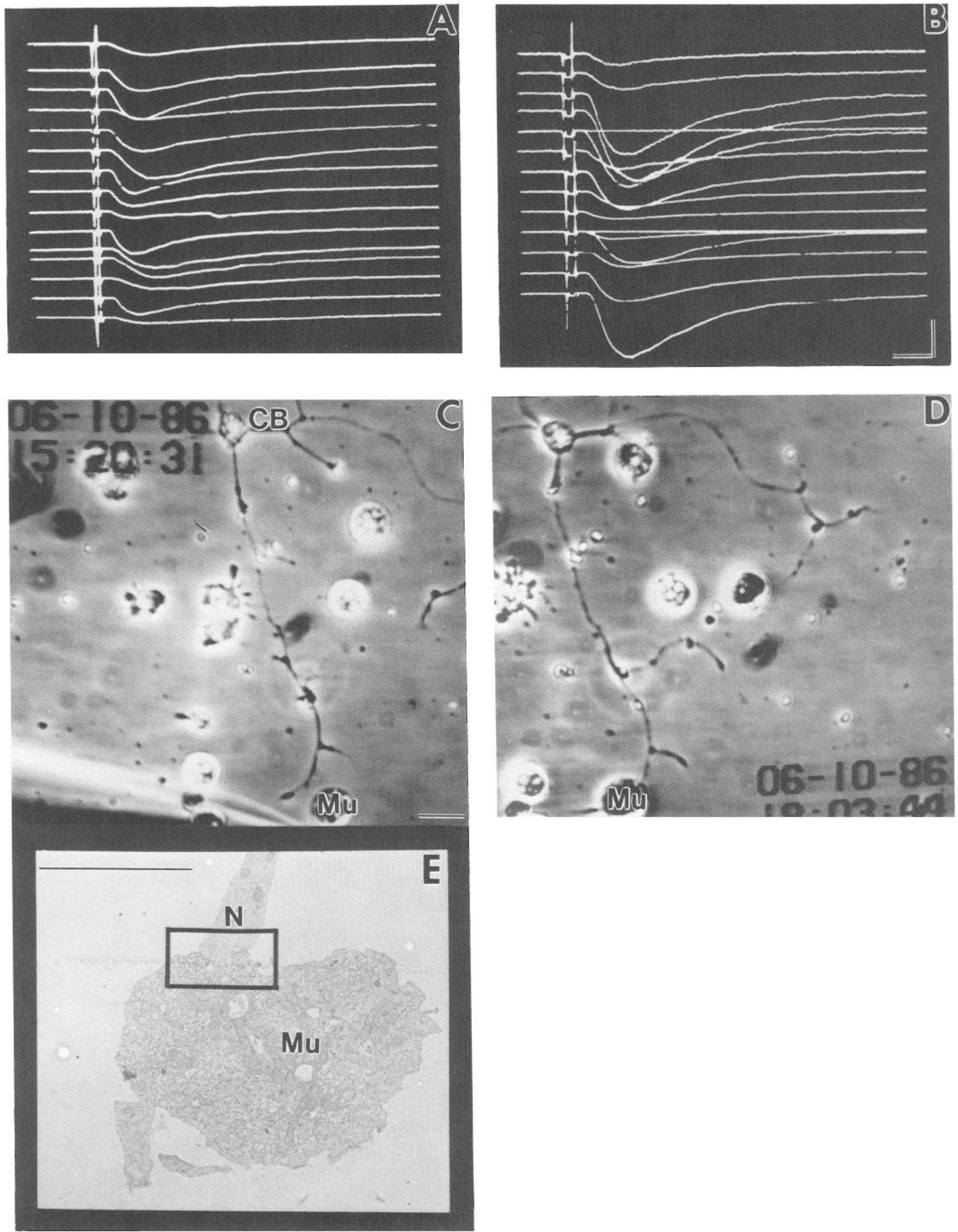

Figure 6. Three hour contact. $A$ and $B$, Recordings of evoked synaptic currents at beginning and end of $3 \mathrm{hr}$ contact period, respectively. Scales: $5 \mathrm{msec}, 250 \mathrm{pA}$. $C$ and $D$, Light-microscopic images of the cells at the beginning and the end of the contact period, respectively. Neuron cell body 

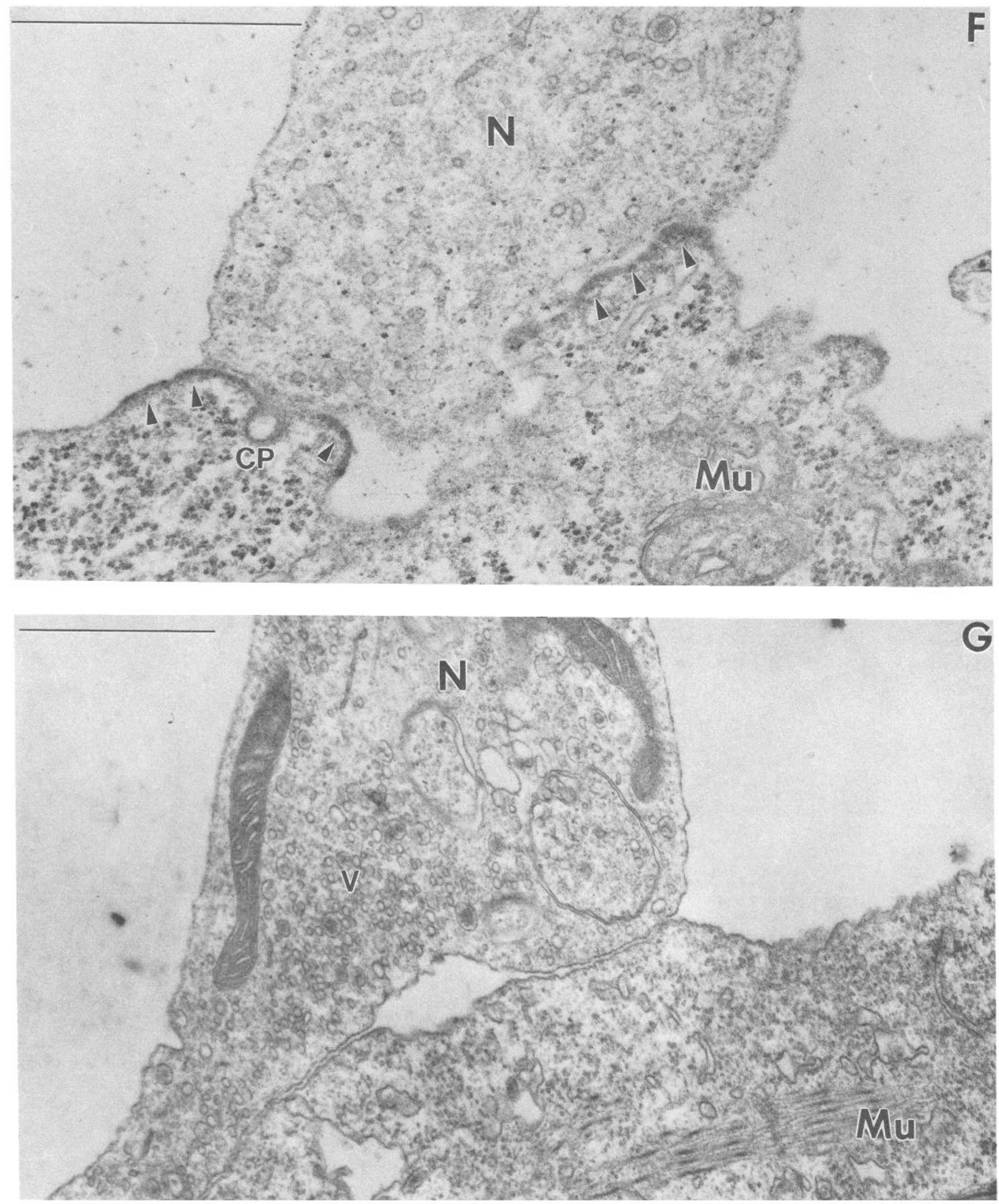

is indicated $(C B)$. Scale bar, $30 \mu \mathrm{m} . E$, Low-magnification micrograph shows the neurite $(N)$ in contact with the myoball $(M u)$. Scale bar, $5 \mu \mathrm{m}$. $F$, Higher magnification of boxed area in $E$, showing thickening of postsynaptic muscle membrane at areas of contact and beyond (arrowheads). Note the coated pit $(C P)$ in myoball. Scale bar, $1 \mu \mathrm{m}$. $G$, Another section of the same contact shows an abundance of clear vesicles $(V)$ in cytoplasm of neurite $(N)$ but no thickening of muscle membrane. Cleft measures $20 \mathrm{~nm}$. Scale bar, $1 \mu \mathrm{m}$. 


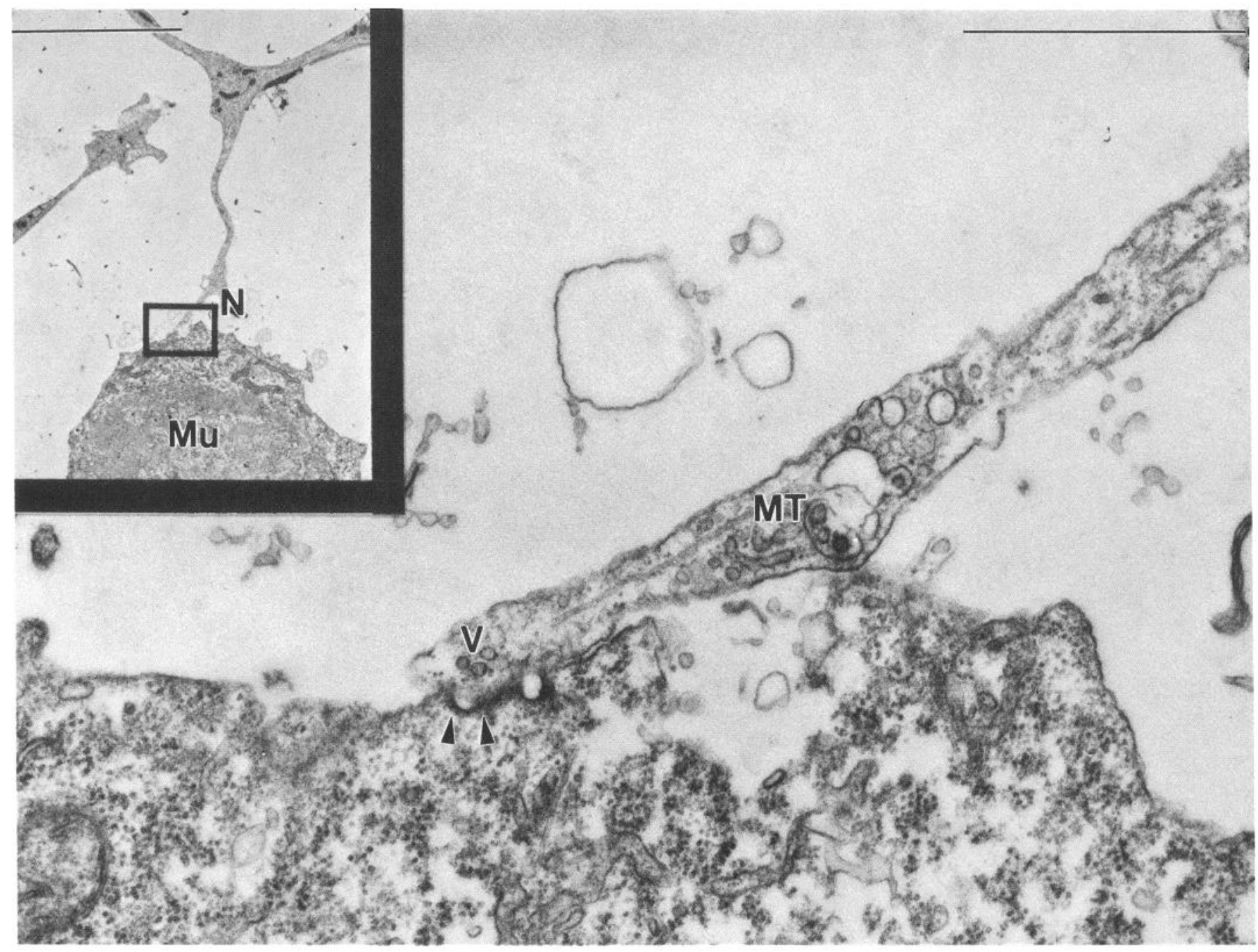

Figure 7. Natural contact. Insert, Low-magnification micrograph of a neurite $(N)$ in contact with a myoball $(M u)$. Scale bar, $10 \mu \mathrm{m}$. Highermagnification micrograph shows the contacting filopodia, which contains clear vesicles $(V)$ and microtubules $(M T)$. A coated pit was found in the muscle $(M u)$ at the contact site (arrowheads). Scale bar, $1 \mu \mathrm{m}$.

hesive areas (focal contacts), which persist for 10-20 min, give rise to larger, more stable focal adhesions that may last for hours (Woods et al., 1983). We have identified focal contacts in a 40 min manipulated contact and a focal adhesion site in a $1 \mathrm{~d}$ natural contact. What role these transient structures have in the development of adhesion and the appearance of defined synaptic structure remains to be clarified.

It is possible that the process of applying the myoball directly to the growth cone somehow accelerates the development of adhesion, which in turn may speed up synapse formation. With manipulation, the time required for the growth cone to make contact with the target muscle is greatly reduced. Thus, adhesion develops within the first few minutes of contact (Evers et al., 1989), and definitive synaptic structure is evident within $3 \mathrm{hr}$.

\section{Coated pits and vesicles}

In many of the contacts examined, we observed a greater frequency of coated pits and vesicles at the contact zones, in either or both the nerve and muscle cells. Recently, these structures have been found at the site of cell-substratum adhesion sites in fibroblasts (Woods et al., 1983) and hepatocytes (Nermut et al.,
1986). In grasshopper embryos, filopodia of growth cones insert into the "guide-post" cell along the pathway of nerve growth, and coated pits and coated vesicles form near the insertion sites (Bastiani and Goodman, 1984). The latter authors suggest that these structures play a role in the information transfer during the interaction of growth cone with the contacted cell. Similar endocytotic events were also seen at the base of filopodia in growth cones within developing chick optic tectum (Cheng and Reese, 1985) and in other developing systems (Altman, 1971; Rees et al., 1976; Rees, 1978).

Coated vesicles were also observed at higher frequency in the subsynaptic sarcoplasm of developing neuromuscular junctions (Matthews-Bellinger and Salpeter, 1983) and in the cytoplasm of cultured chick myotube under the ACh receptor clusters (Burrage and Lentz, 1981; Bursztajn and Fischbach, 1984). Luther et al. (1987) also detected coated pits and vesicles in association with $\mathrm{ACh}$ receptor clusters in both aneural and postjunctional muscle cells from Xenopus nerve-muscle cultures. It is unknown whether the coated vesicles observed were produced by endocytotic activity via localized formation of coated pits or were preferentially transported there for exocytotic insertion of newly 

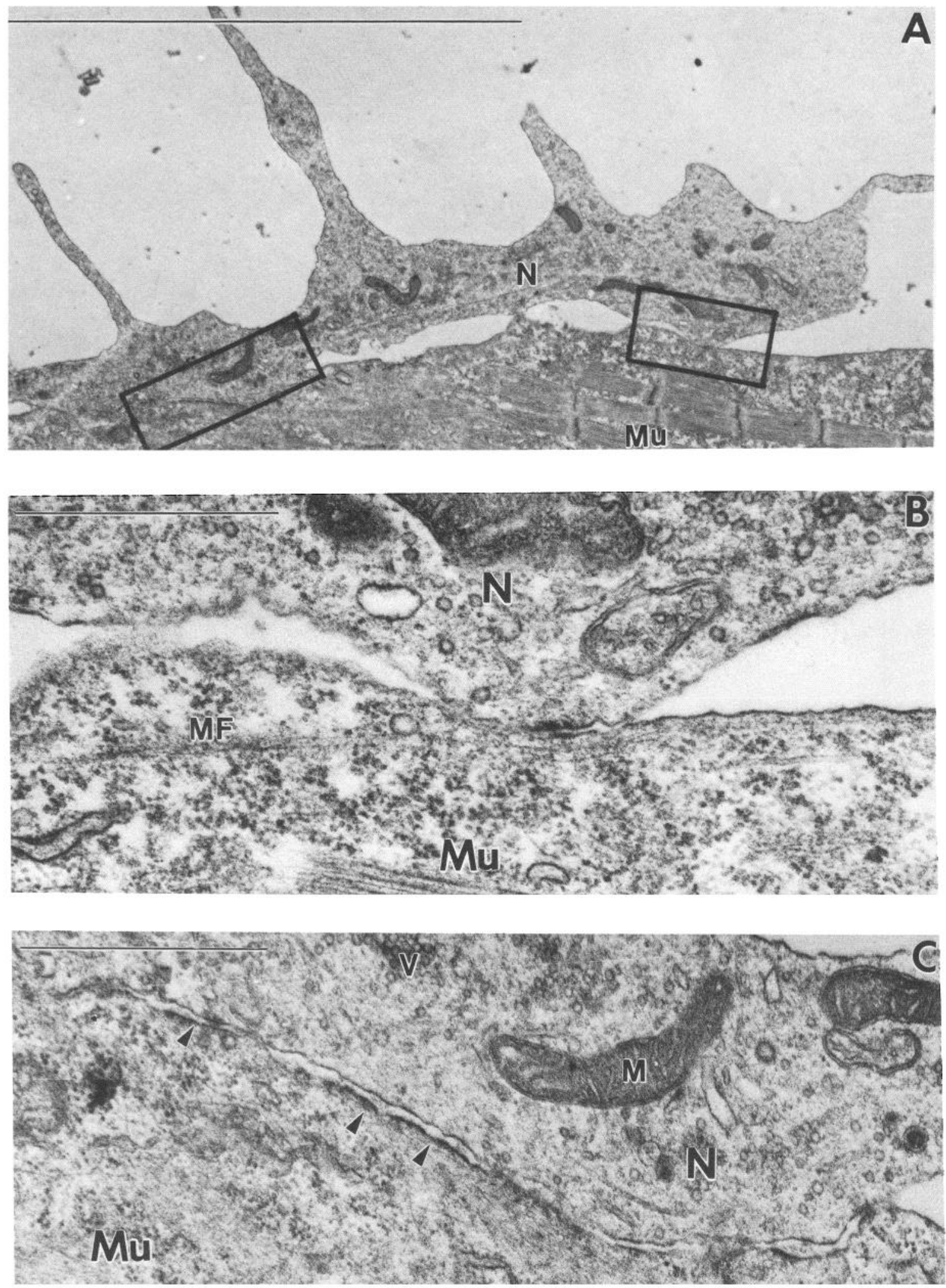

Figure 8. Natural contact. $A$, Low-magnification micrograph of a neurite $(N)$ contacting along the length of a muscle cell $(M u)$. Scale bar, $10 \mu \mathrm{m}$. $B$ and $C$, Higher-magnification micrographs of boxed areas in $A$ show temporal sequence of morphological changes. In $B$, more recent contact shows focal adhesion site between nerve and muscle, with increased density of the membrane. Microfilaments $(M F)$ are found near the adhesion site. Gap between contacting membrane measures about $8 \mathrm{~nm}$. Scale bar, $1 \mu \mathrm{m}$. In $C$, older contact shows thickening (arrowheads) of the muscle membrane, with widened gap between the contacting membranes. Scale bar, $1 \mu \mathrm{m}$. 

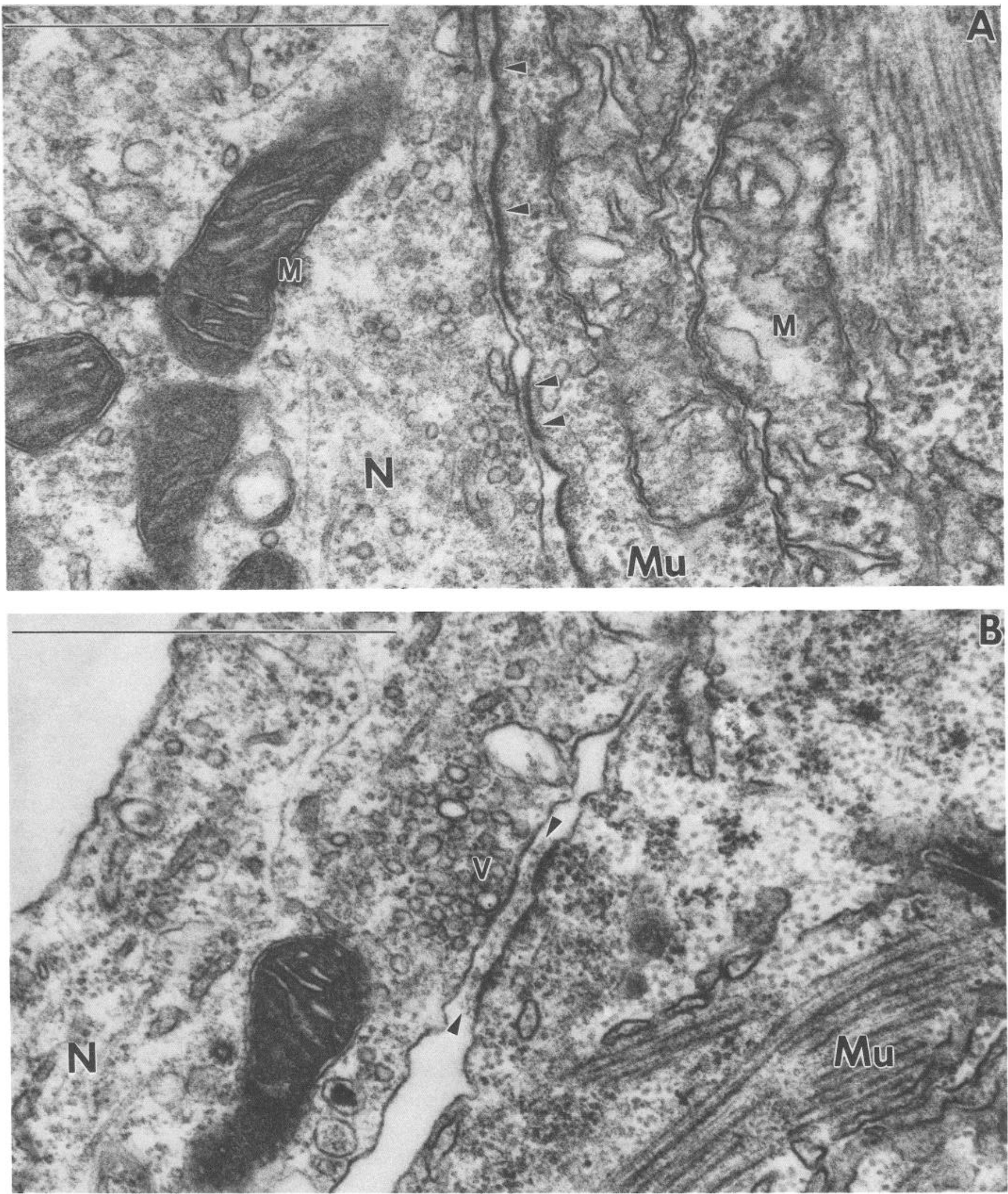

Figure 9. Natural contact. Two other sections of the same contact as that shown in Figure 8, but more distant from the growth cone and presumably at later stages of development. $A$, Marked thickening and infolding of muscle membrane (arrowheads). Scattered vesicles $(V)$ are present in the nerve $(N)$. Basal lamina is evident in the cleft, which measures $10-40 \mathrm{~nm}$. Scale bar, $1 \mu \mathrm{m}$. B. Cleft widens to $50 \mathrm{~nm}$ and is filled with basal lamina material (arrowheads). Vesicles appear to cluster against presynaptic nerve membrane. Scale bar, $1 \mu \mathrm{m}$. 
synthesized membrane components. In either case, the rapid appearance of coated pits within tens of minutes of contact suggests a rapid and localized induction of metabolic activity at the contact site. Diffusible "trophic" factors released by the contacting cell could serve as extracellular ligands for the induction of coated pit formation. Ligand-induced coated pit formation is known to occur within minutes in many cell types (see Pastan and Willingham, 1985).

\section{Basal lamina and synaptic cleft}

The extracellular matrix may play important roles in the cellcell interactions during synaptogenesis (see Sanes, 1983). Synapse-specific molecules are found in the basal lamina of developing junctions and associated with the $\mathrm{ACh}$ receptor clusters of developing muscle cells (Weinberg et al., 1981; Anderson and Fambrough, 1983; Anderson et al., 1984). Mature synaptic basal lamina contains molecule(s) that can induce pre- and postsynaptic differentiation during the regeneration of the frog neuromuscular junction (Nitkin, et al., 1983). In most of the early contacts there was little evidence of basal lamina formation. The close membrane appositions found in early contacts indicates that nerve-muscle interaction must occur in the absence of basal lamina. This suggests that if the synaptic organizing molecules, e.g., agrin (Nitkin et al., 1987), are involved in the early phases of synaptogenesis, they must act prior to significant development of basal lamina. Our results, however, are consistent with the idea that presynaptic differentiation is induced by the basal lamina containing molecules, since the former appears only after the formation of basal lamina. The widening of the extracellular gap occurs concurrently with the deposition of basal lamina. Perhaps basal lamina molecules are responsible for the separation of nerve and muscle membranes by breaking and replacing the molecular bonds that cause the close membrane apposition.

\section{Structural requirement for functional synaptic transmission}

The pulsatile nature of spontaneous $\mathrm{ACh}$ release and the amplitude fluctuation of the cvokcd synaptic current suggest that vesicular release of $\mathrm{ACh}$ is the basic mechanism for synaptic transmission at these early contacts (Evers et al., 1989). The fact that the growth cones and neurites of the early contacts lacked active zones yet showed efficient evoked ACh release (Sun and Poo, 1987) argues that such specializations are not necessary for transmitter release. Since there is no apparent preferential clustering of vesicles near the presynaptic membrane, rapid translocation of the vesicles (within 1-3 msec after the arrival of action potential) to the plasma membrane must occur. The relative paucity of synaptic vesicles at many of the early functional contacts (see Fig. $3 D$ ) also demands rapid recycling of synaptic vesicles, a process that may involve the coated pits observed frequently in the contacting neurite.

The increase in evoked synaptic response during the first 12 $\mathrm{hr}$ of nerve-muscle contact also occurred in the absence of definitive presynaptic differentiation. However, marked thickening of postsynaptic muscle membrane was observed within 3 $\mathrm{hr}$ of contact. Such membrane thickening most likely reflects an accumulation of integral or peripheral membrane components, including possibly $\mathrm{ACh}$ receptors. Accumulation of $\mathrm{ACh}$ receptors at contact sites could explain the increased amplitude of evoked synaptic currents. Kidokoro et al., (1980) have observed a close correlation between the size and frequency of spontaneous synaptic potentials and the extent of ACh receptor clusters at the nerve-muscle contacts in Xenopus culture, although the precise duration of the contacts was unknown.

\section{Conclusion}

By examining the fine structure of early functional synaptic contacts, we have identified morphological features that may play important roles in the early phases of synaptogenesis. These features-focal adhesion sites, close membrane apposition, coated pits and vesicles, and membrane thickening-may provide clues to the cellular events involved in the early nervemuscle interaction, namely, cell-cell recognition, development of selective adhesion, and induction of localized membrane traffic. These features appeared rapidly following the contact, prior to the development of synaptic specializations. Whether they are a prercquisite for normal synaptic development remains to be studied.

\section{References}

Abercrombie M., J. E. M. Heaysman, and S. M. Pegrum (1971) The locomotion of fibroblasts in culture. IV. Electron microscopy of the leading lamella. Exp. Cell Res. 67: 359-367.

Altman, J. (1971) Coated vesicles and synaptogenesis. A developmental study in the cerebellar cortex of the rat. Brain Res. 30:311322.

Anderson, M. J., and M. W. Cohen (1977) Nerve-induced and spontaneous redistribution of acetylcholine receptors on cultured muscle cells. J. Physiol. (Lond.) 268: 757-773.

Anderson, M. J., and D. M. Fambrough (1983) Aggregates of acetylcholine receptors are associated with plaques of a basal lamina heparan sulfate proteoglycan on the surface of skeletal muscle fibers. J. Cell Biol. 97: 1396-1411.

Anderson, M. J., F. G. Klier, and K. E. Tanguay (1984) Acetylcholine receptor aggregation parallels the deposition of a basal lamina proteoglycan during development of the neuromuscular junction. J. Cell Biol. 99: 1769-1784.

Bastiani, M. J., and C. S. Goodman (1984) Neuronal growth cones: Specific interactions mediated by filopodial insertion and induction of coated vesicles. Proc. Natl. Acad. Sci. USA 81: 1849-1853.

Blackshaw, S., and A. Warner (1976) Onset of acetylcholine sensitivity and endplate activity in developing myotome muscles of Xenopus. Nature 262: 217-218.

Bloch, R. J., and B. Geiger (1980) The localization of acetylcholine receptor clusters in area of cell-substrate adhesion in cultures of rat myotubes. Cell 21: 25-35.

Buchanan, J., Y.-A. Sun, and M.-M. Poo (1987) Morphology of developing neuromuscular junction during the first few hours of functional contact. Soc. Neurosci. Abstr. 13: 1423.

Burrage, T. G., and T. L. Lentz (1981) Ultrastructural characterization of surface specializations containing high-density actylcholine receptors on embryonic chick myotubes in vivo and in vitro. Dev. Biol. 85 : 267-286.

Bursztajn, S., and G. D. Fischbach (1984) Evidence that coated vesicles transport acetylcholine receptors to the surface membrane of chick myotubes. J. Cell Biol. 98: 498-506.

Changeux, J. P., A. Devillers-Thiery, and P. Chemouilli (1984) The acetylcholine receptor: An allosteric protein engaged in intercellular communication. Science 225: 1335-1345.

Cheng, T. P. O., and T. S. Reese (1985) Polarized compartmentalization of organelles in growth cones from developing optic tectum. J. Cell Biol. 101: 1473-1478.

Chow, I., and M.-M. Poo (1985) Release of acetylcholine from embryonic neurons upon contact with muscle cell. J. Neurosci. 5: 10761082.

Coulter, H. D. (1967) Rapid and improved methods for cmbedding biological tissues in Epon 812 and Araldite 502. J. Ultrastruct. Res. 86: $107-118$.

Dennis, M. J. (1981) Development of the neuromuscular junction: Inductive interactions between cells. Annu. Rev. Neurosci. 4: 43-68.

Evers, J., M. Laser, Y.-a. Sun, Z.-p. Xie, and M.-m. Poo (1989) Studies of nerve-muscle interactions in Xenopus cell culture: Analysis of early synaptic currents. J. Neurosci. 9: 1523-1539. 
Forscher, P., L. K. Kaczmarek, J. Buchanan, and S. J. Smith (1987) Cyclic AMP induces changes in distribution and transport of organelles within growth cones of Aplysia bag cell neurons. J. Neurosci. 7: 3600-3611.

Hamill, O., A. Marty, E. Neher, B. Sakmann, and F. J. Sigworth (1981) Improved patch-clamp techniques for high-resolution current recording from cells and cell-free membrane patches. Pfluegers Arch. 391: 85-100.

Kelly, A. M., and S. I. Zacks (1969) The fine structure of motor endplate morphogenesis. J. Cell Biol. 42: 154-169.

Kidokoro, Y., and E. Yeh (1982) Initial synaptic transmission at the growth cone in Xenopus nerve-muscle cultures. Proc. Natl. Acad. Sci. USA 79: 6727-6731.

Kidokoro, Y., M. J. Anderson, and R. Gruencr (1980) Changes in synaptic potential properties during acetylcholine receptor accumulation and neurospecific interactions in Xenopus nerve-muscle cell culture. Dev. Biol. 78: 464-483.

Kullberg, K. W., T. L. Lentz, and M. W. Cohen (1977) Development of the myotomal neuromuscular junction in Xenopus laevis: An electrophysiological and fine structural study. Dev. Biol. 60: 101-129.

Landis, S. C. (1983) Neuronal growth cones. Annu. Rev. Physiol. 45: 567-580.

Luther, P. W., R. J. Bloch, J. Strong, and D. W. Pumplin (1987) Deepetch replication of cytoplasmic structures associated with isolated AChR aggregates. J. Cell Biol. 105: 290a.

Matthews-Bellinger, J. A., and M. M. Salpeter (1983) Fine structural distribution of acetylcholine receptors at developing mouse neuromuscular junctions. J. Ncurosci. 3: 644-657.

McCarthy, M. P., J. P. Earnest, E. F. Young, S. Choe, and R. M. Stroud (1986) The molecular neurobiology of the acetylcholine receptor. Annu. Rev. Neurosci. 9: 383-413.

McDonald, K. (1984) Osmium ferricyanide fixation improves microfilament preservation and membrane visualization in a variety of animal cell types. J. Ultrastruct. Res. 86: 107-118.

Moore, M. J. (1975) Removal of glass coverslips from cultures flat embedded in epoxy resins using hydroflouric acid. J. Microsc. 104: 205-207.

Nakajima, Y., Y. Kidokoro, and F. G. Klier (1980) The development of functional junctions in vitro: An ultrastructural and physiological study. Dev. Biol. 77: 52-72.

Nermut, M. V., L. D. Williams, and S. C. Stamatoglou (1986) Ultrastructure of ventral membranes of rat hepatocytes spread on typc IV collagen. Eur. J. Cell Biol. 42: 35-44.

Nieuwkoop, P. D., and J. Faber (1967) Normal Table of Xenopus laevis (Daudin), 2nd ed., North Holland, Amsterdam.

Nitkin, R. M., B. G. Wallace, M. E. Spira, E. W. Godfrey, and U. J. McMahan (1983) Molecular components of the synaptic basal lamina that direct differentiation of regenerating neuromuscular junctions. Cold Spring Harbor Symp. Quant. Biol. 48: 653-666.

Nitkin, R. M., M. A. Smith, C. Magill, J. R. Fallon, Y. M. Yao, B. G. Wallace, and U. J. McMahan (1987) Identification of agrin, a synaptic organizing protein from Torpedo electric organ. J. Cell Biol. 105: $2471-2478$.

Pastan, I., and M. C. Willingham (1985) The pathway of endocytosis. In Endocytosis, I. Pastan and M. C. Willingham, eds., pp. 1-44, Plenum, New York.
Peng, H. B., P. C. Bridgman, S. Nakajima, A. Greenberg, and Y. Nakajima (1979) A fast development of presynaptic function and structure of the neuromuscular junction in Xenopus tissue culture. Brain Res. 169: 379-384.

Peng, H. B., Y. Nakajima, and P. C. Bridgman (1980) Development of the post-synaptic membrane in Xenopus neuromuscular cultures observed by freeze fracture and thin section electron microscopy. Brain Res. 196: 11-31.

Rash, J. E., C. S. Hudson, and M. H. Ellisman (1978) Ultrastructure of acetylcholine receptors at the mammalian neuromuscular junction. In Cell Membrane Receptors for Drugs and Hormones: A Multidis ciplinary Approach, R. W. Straub and L. Bolis, eds., pp. 47-68, Raven, New York.

Rees, R. P. (1978) Inclusion in coated vesicle membrane as the transport mechanism for acetycholine receptor molecules in isolated cultured sympathetic neurons. J. Cell Biol. 79: 99a.

Rees, R. P., M. B. Bunge, and R. P. Bunge (1976) Morphological changes in neurite growth cone and target neuron during synaptic junction development in culture. J. Cell Biol. 68: 240-263.

Rosenbluth, J. (1974) Substructure of amphibian motor end plate: Evidence for a granular component projecting from the outer surface of the receptive membrane. J. Cell Biol. 62: 755-766.

Sanes, J. R. (1983) Roles of extracellular matrix in neural development. Annu. Rev. Physiol. 45: 581-600.

Spitzer, N. C, and J. C. Lamborghini (1976) The development of the action potential mechanism of amphibian neurons isolated in culture. Proc. Natl. Acad. Sci. USA 73: 1641-1645.

Sun, Y.- $\Lambda$., and M.-M. Poo (1987) Evoked release of acetylcholine from the growing embryonic neuron. Proc. Natl. Acad. Sci. USA 84 . $2540-2544$.

Takahashi, T., Y. Nakajima, K. Hirosawa, S. Nakajima, and K. Onodera (1987) Structure and physiology of developing neuromuscular synapses in culture. J. Neurosci. 7: 473-481.

Teräväinen, $H$. (1968) Development of myoneural junction in the rat. Z. Zellforsch. Mikros. Anat. 87: 249-265.

Tosney, K. W., and N. K. Wessells (1983) Neuronal motility: The ultrastructure of veils and microspikes correlates with their motile activities. J. Cell Sci. 61: 389-411.

Weinherg, C. B., J. R. Sanes, and Z. W. Hall (1981) Formation of neuromuscular junctions in adult rats: Accumulation of acetylcholine receptors, acetylcholinesterase and components of synaptic basal lamina. Dev. Biol. 84: 255-268.

Weldon, P. R., and M. W. Cohen (1979) Development of synaptic ultrastructure at neuromuscular contacts in an amphibian cell culture system. J. Neurocytol. 8: 239-259.

Woods, A., Smith, C. G., Rees, D. A., and G. Wilson (1983) Stages in specialization of fibroblast adhesion and deposition of extracellular matrix. Eur. J. Cell Biol. 32: 108-116.

Xie, Z.-P., and M.-M. Poo (1986) Initial events in the formation of neuromuscular synapse: Rapid induction of acetylcholine release. Proc. Natl. Acad. Sci. USA 83: 7069-7073.

Yamada, K. M., Spooner, B. S., and N. K. Wessells (1971) Ultrastructure and function of growth cones and axons of cultured nerve cells. J. Cell Biol. 49: 614-635. 